УДК 902.01

https://doi.org/10.24852/2587-6112.2021.4.110.121

\title{
СЫРОДУТНЫЕ ГОРНЫ НИЖНЕЙ АНГАРЫ: НЕКОТОРЫЕ ИТОГИ ИЗУЧЕНИЯ
}

\section{(C) 2021 г. П.В. Мандрыка, П.О. Сенотрусова}

В статье приводятся новые материалы из южнотаежной зоны Нижнего Приангарья по теплотехническим объектам раннего железного века, Средневековья и Нового времени, использовавшимся для получения металлического железа из рудного. Приводятся источники по их археологическому изучению, степени сохранности и радиоуглеродной датировке. На основе особенностей конструкции сыродутные горны для получения железа разделены на три типа: с камерой цилиндрической формы из глины; с камерой кубическо-цилиндрической формы, сложенной из камней и глины; с камерой кубической формы, вылепленной из глинистой почвы. Сыродутные горны в обязательном порядке имели основания, устроенные в яме. К индивидуальным и хронологическим особенностям горнов отнесены форма камер, их устройство, присутствие плоских камней на дне плавильных камер, способы возведения наземных надстроек, использование органических материалов при их сооружении, наличие или отсутствие пригорновых ям. Горны с цилиндрической камерой из глины использовались в районе исследования на всем протяжении эпохи металла, их изменение во времени связано с устройством дна камеры. Горны с кубовидной камерой изменяются во времени по использованию материала строительства: ранние сделаны из глинистых почв, поздние - из камней и глины. Выделенные типы горнов на Нижней Ангаре близки между собой и отражают развитие одной технологической традиции, появившейся в тесинское время с распространением памятников шилкинской культуры, входящей в круг культур хуннского мира.

Ключевые слова: археология, Нижнее Приангарье, ранний железный век, средневековье, металлургия, сыродутный горн, хронология.

\section{CATALON FURNACES OF LOWER ANGARA: PRELIMINARY STUDY RESULTS}

\section{P. V. Mandryka, P. O. Senotrusova}

The paper features new materials from the southern taiga zone of the Lower Angara region on thermal engineering objects of the early Iron Age, the Middle Ages and the New Age, which were used to produce metallic iron from ore. Sources for their archaeological study, state of preservation and radiocarbon dating are provided. Based on the design features, catalon furnaces for iron production are subdivided into the following three types: with a cylindrical chamber made of clay; with catalon furnaces had foundations arranged in pits. The shape of chambers, their structure, the presence of flat stones at the bottom of the smelting chambers, the methods of erecting ground superstructures, the use of organic materials in their construction, and the presence or absence of furnace pits are considered as the individual and chronological features of the furnaces. Furnaces with a cylindrical chamber made of clay were used in the study area throughout the Metal Age, and their change over time is associated with the structure of the chamber bottom. Furnaces with a cubic chamber had changed over time in terms of the use of the construction material: the early ones are made of clay soils, the later ones - of stones and clay. The identified types of Lower Angara furnaces are similar to each other and reflect the development of a single technological tradition which emerged in the Tesino period along with the spread of the monuments of Shilka culture forming a part of the Hunnic world cultures.

Keywords: archaeology, Lower Angara region, the Early Iron Age, the Middle Ages, metallurgy, catalon furnace, chronology.

\section{Введение}

Вопросы времени освоения и способы получения кричного железа в Древности и Средневековье в долине нижнего течения реки Ангары неоднократно поднимались российскими исследователями. Первые свидетельства металлургических объектов здесь были задокументированы А.П. Окладниковым в 1937 г., который отмечал железные шлаки в культурных слоях поселений вместе со средневековой керамикой, украшенной оригинальным тонким гребенчатым орнаментом. Исследователем изучены и небольшие сыродутные горны, не превышающие высоту 40 см и диаметром 25-30 см (Окладников А.П., 1937). Масштабные раскопки металлургических комплексов были проведены им только в верховьях Ангары на островах Сосновом 
и Лесном (Окладников А.П., 1952; 1953). В последней четверти XX в. свидетельства черной металлургии изучались на многих памятниках по ангарским берегам, но достаточно полно опубликованы лишь материалы со стоянок в устьях рр. Илим, Кова, Пашина, Чадобец и Карабула (Васильевский, Аксенов, 1971, с. 164; Гладилин, 1985; Леонтьев, Дроздов, 2005; Макаров, 2013, с. 134).

А.В. Гладилиным (1985) на материалах четырех памятников (стоянки Чадобец, УстьКова, Усть-Чадобец и в Пашина) были выделены четыре вида теплотехнических сооружений и предложена схема их развития, основанная на усложнении конструкции. По мнению исследователя, горны-сосуды (1 вид: большие сосуды, внутрь которых засыпались руда и уголь, а воздух подавался через сопло) и горны простейшего ямного устройства (2 вид: в виде углубления в земле, обмазанного глиной) относятся к IV-II вв. до н. э. Горны с фурмой (3 вид: усовершенствование второго, к камере, устроенной в ямы с обмазанными глиной стенками, воздух нагнетался через подземный фурмовой проход) относятся к таштыкскому времени, а печи на фундаменте (4 вид: наземные цилиндрической формы, стенки и фундамент сложены из каменных плит, которые углублены в яму и обмазаны глиной) с увеличенной плавильной камерой к Средневековью и Новому времени.

С началом широкомасштабных работ по сохранению археологического наследия в зоне затопления водохранилища Богучанской ГЭС в 2008-2012 гг. обнаружены многочисленные новые данные, свидетельствующие о производстве железа в долине Ангары. Отражены они в статьях А.А. Адамова и П.Г. Данилова (2010), П.Б. Амзаракова и О.В. Ковалевой (2010), Ю.А. Гревцова, Д.Н. Лысенко и Л.Л. Галухина (2010), А.В. Постнова (2010); Е.П. Рыбина, А.А. Кубан, М.Н. Мещерина и Я.В. Фролова (2010), Ю.Н. Гаркуши, А.Е. Гришина, Ж.В. Марченко, Е.А. Казаковой и А.А. Дудко (2012) и полевых отчетах других исследователей, а также в монографиях (Богучанская..., 2015; Стоянка ..., 2016). Имеются сведения о сыродутных горнах, устроенных на берегах наибольших притоков Ангары, в частности на р. Муре (Сенотрусова, 2013; Мандрыка, Сенотрусова, 2013; Мандрыка, Сенотрусова, 2014). Вместе с этими информационными публикациями начинают появляться аналитические статьи о производственных площадках и кричных горнах, о сырье, кузнечном деле и инструментарии древних металлургов
(Князева и др. 2011; Князева, 2011; Кондратов, 2011; Мандрыка, Князева, 2011; Мандрыка и др., 2012; Senotrusova end Mandryka, 2015; Сенотрусова, Самородский, Мандрыка, 2016; Голубева, 2016). Представленными работами накоплена информация, которая требует обобщения и систематизации.

\section{Сыродутные горны нижней Ангары}

Не все виды сыродутных горнов из отмеченных А.В. Гладилиным встречены в ходе широкомасштабных раскопочных работ последних лет. Остались неизвестными тиглисосуды, в которых восстанавливалось металлическое железо из рудного, а также ямные горны с фурмовым проходом под землей.

По имеющимся новым данным, сыродутные горны из Нижней Ангары по устройству можно разделить на три типа.

Тип 1. Полуподземные горны с камерой цилиндрической формы, в диаметре круглые, стенки выполнены из слоя глины толщиной 4-6 см (рис. 1, 2). Основанием они устраивались в яме несколько больших размеров, чем рабочая камера. В некоторых сохранившихся горнах дном камеры служил плоский камень (на поселениях Проспихинская Шивера-I и IV) или дно оставалось земляным (Пашина, объект 12). Наземная часть продолжала подземную и повторяла ее цилиндрическую форму. Горны различаются размерами камер: внутренний диаметр от 10-12 до 25 см, при глубине сохранившейся подземной части от 10-17 до 50 см. В заполнении камер горнов отмечена углистая почва, отдельные куски шлака. Достаточно часто в культурных слоях поселений печи этого типа разрушены полностью, но от них сохраняются разбросанные по слою куски глиняной обмазки, шлаки и пятна прокаленной почвы. Возле печей иногда отмечаются пригорновые ямы размерами более 1 м и глубиной до 0,3 м. В них фиксируются куски железного шлака и другие находки культурного слоя. Можно предположить, что в них размещались воздуходувные меха. Сопла приставлялись к стенкам камер на уровне древней поверхности.

Тип 2. Полуподземные горны с камерой кубическо-цилиндрической формы, сложенной из камней и глины (рис. 3). Характерными особенностями этих горнов является сооружение нижней части камеры из вертикально поставленных камней, использование для их скрепления глины и органических материалов (деревянные колышки или береста). Вероятно, верхняя, наземная часть этих горнов была изготовлена из глины, на что указывает 


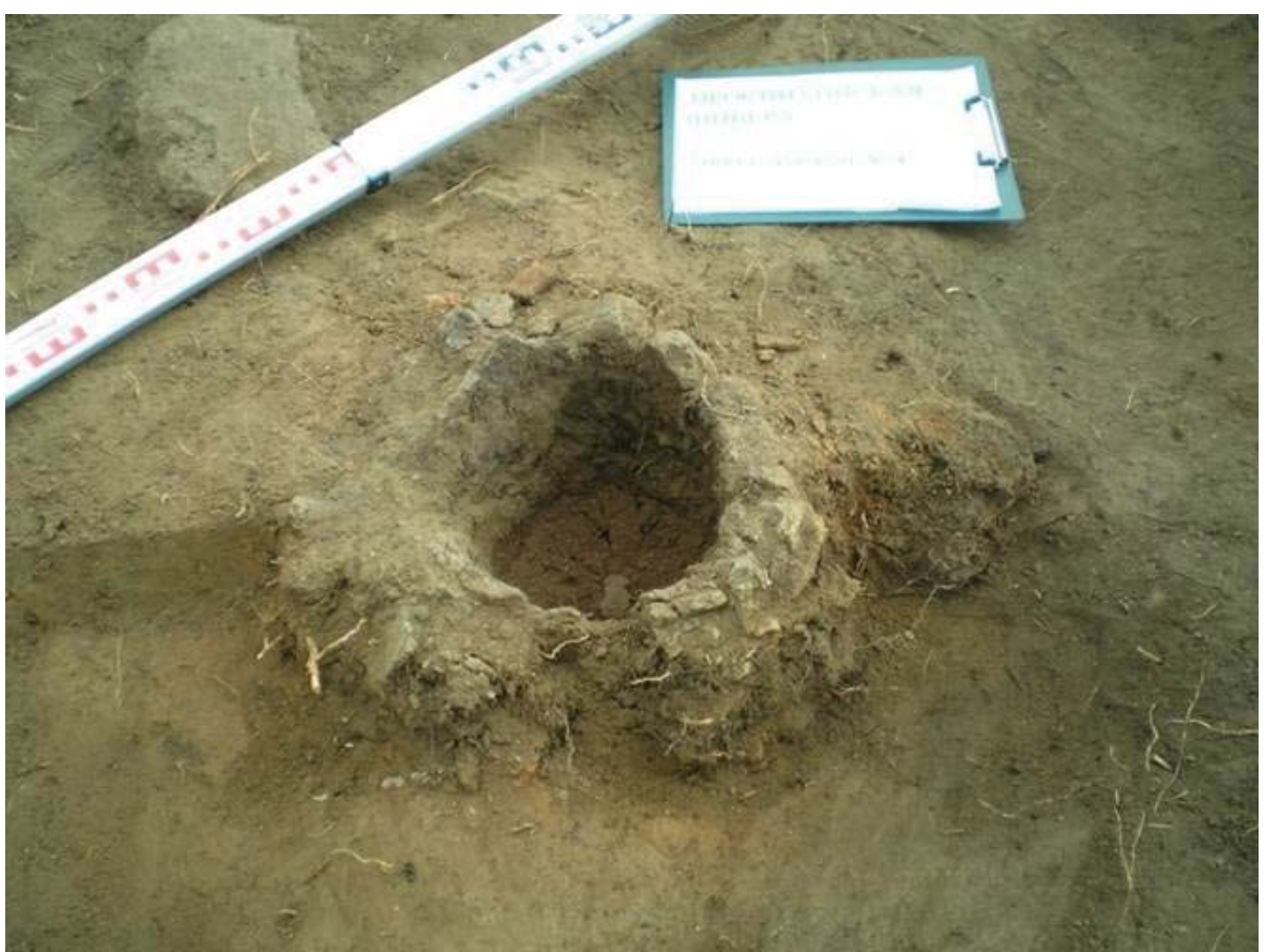

Рис. 1. Горн с камерой цилиндрической формы из глины. Поселение Проспихинская Шивера-I. Раскопки П. В. Мандрыки 2008 г.

Fig. 1. Furnace with a cylindrical chamber made of clay. Prospikhinskaya Shivera-I site. Excavations by P.V. Mandryka, 2008.

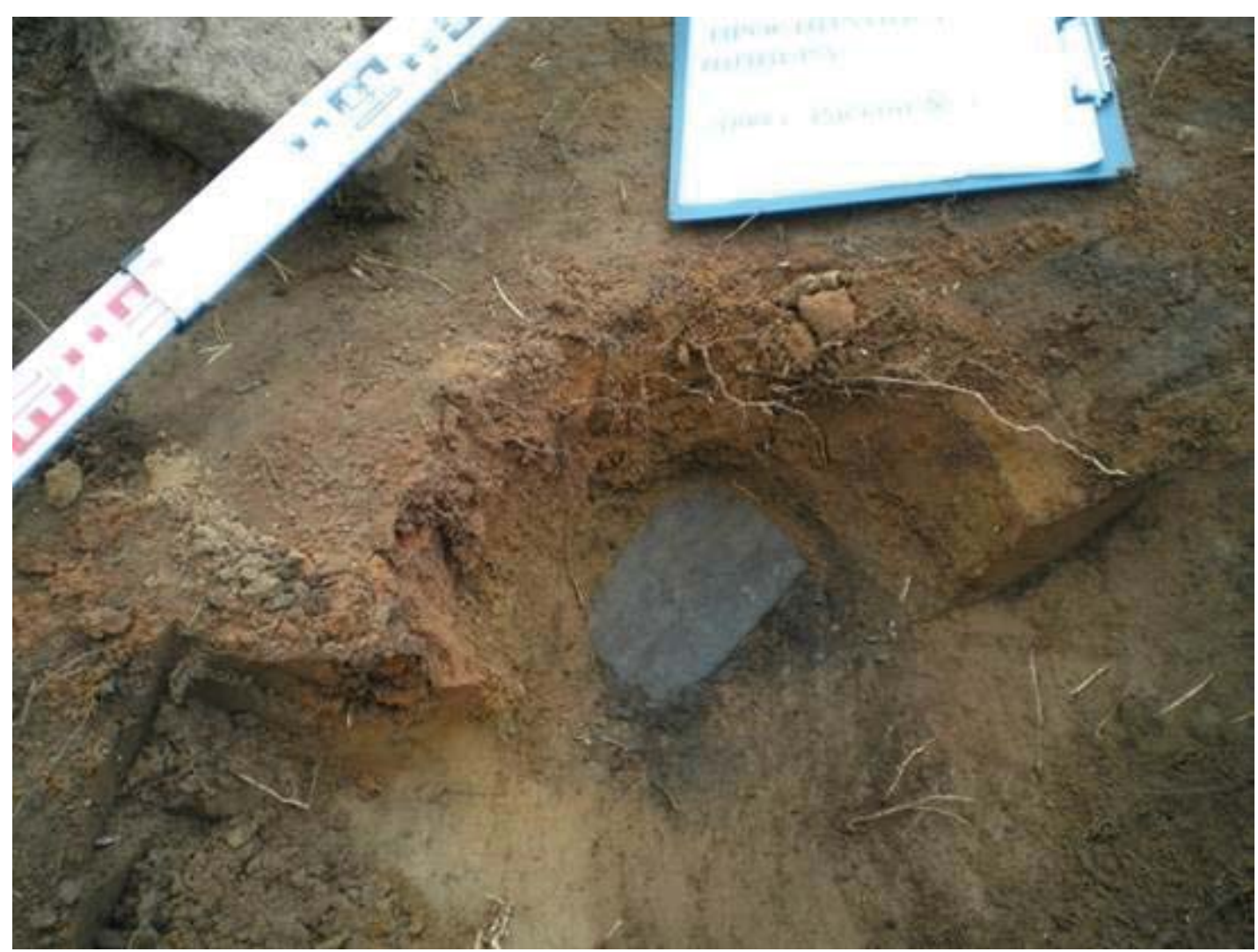

Рис. 2. Плоский камень на дне камеры горна. Поселение Проспихинская Шивера-I. Раскопки П. В. Мандрыки 2008 г.

Fig. 2. Flat stone at the bottom of a furnace chamber. Prospikhinskaya Shivera-I site. Excavations by P.V. Mandryka, 2008. 


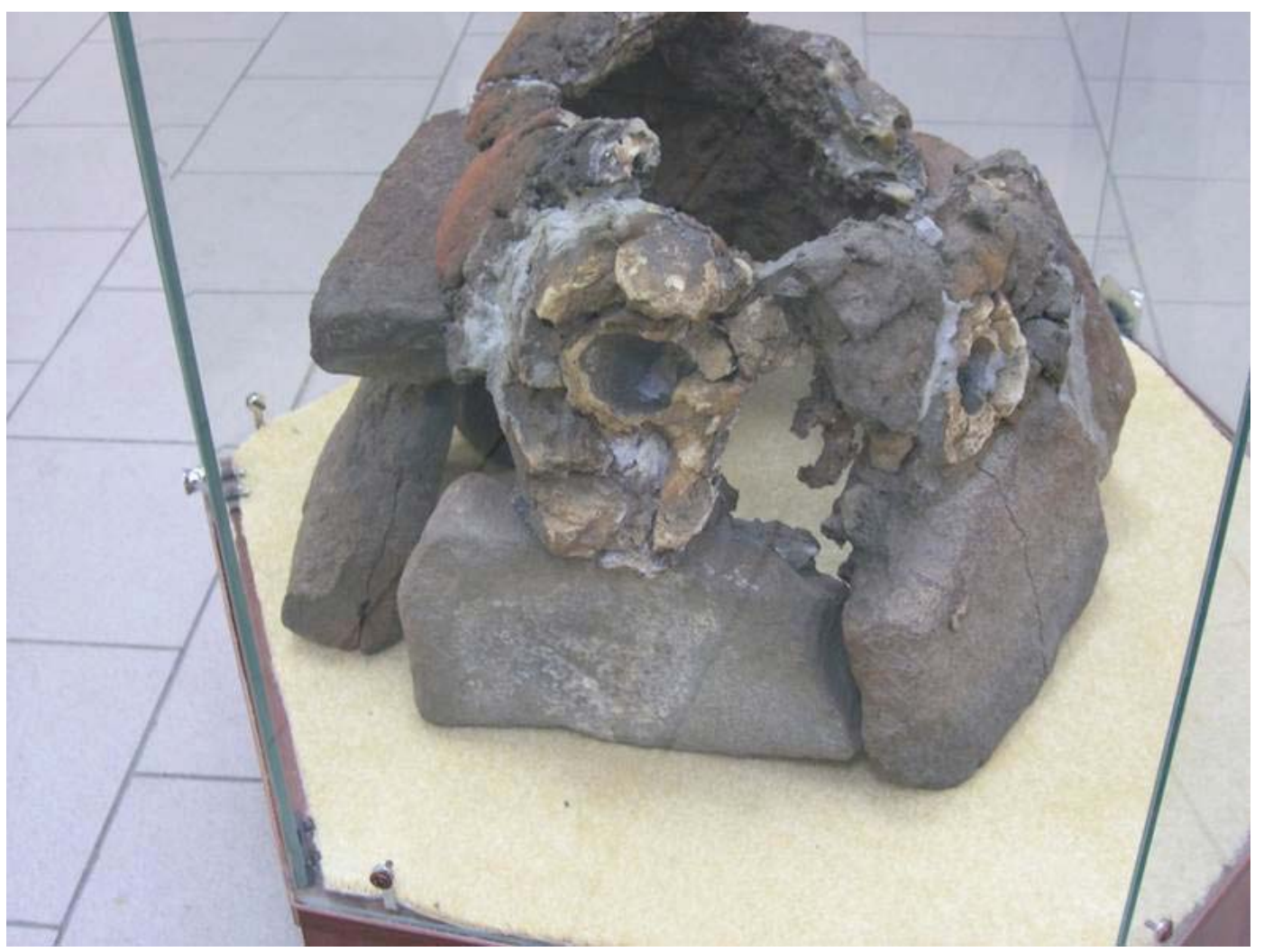

Рис. 3. Горн с камерой кубической формы из камней и глины. Стоянка Пашина. Раскопки Н.И. Дроздова 1976 г. Экспозиция музея археологии Красноярского государственного педагогического университета им. В.П. Астафьева

Fig. 3. Furnace with a cubic chamber made of stones and clay. Pashin site. Excavations by N.I. Drozdov of 1976. Exposition of the Museum of Archaeology of the Krasnoyarsk State Pedagogical University named after V.P. Astafiev

большое число найденных возле них спеченных кусков толщиной до 2-5 см. Наиболее полное представление об этом типе металлургических объектов дают сохранившиеся части домницы стоянки Пашина (Дроздов и др., 1978; Гладилин, 1985; Леонтьев, 1999; и др.), горнов из комплекса Проспихинская ШивераIV (Сенотрусова Самородский, Мандрыка, 2016) и стоянки Усть-Карабула (Макаров, 2013). Плавильные камеры устраивались в яме прямоугольной формы, размеры сохранившихся частей от $16 \times 38$ см глубиной 16 см до $50 \times 75$ см глубиной 16 см. Стенки и дно ямы закрывались камнями-плитками: на дне один камень, по стенкам - четыре или более камней, поставленных на ребро. Объем камер различен, сохранились нижние части размерами $15 \times 12 \times 16 \mathrm{~cm}, 23 \times 25 \times 9 \mathrm{~cm}, 36 \times 37 \times 46 \mathrm{~cm}$. Воздуходувные проходы устраивались с двух противоположных или сопряженных сторон между камнями либо над ними, керамические сопла примазывалось глиной. Со стороны фурмовых проходов к камере примыкали ямы, в которых, очевидно, помещались воздуходувные меха. Заполнение ям состояло из темно-серой супеси с включением древесных углей и пятен прокаленной почвы, здесь же встречаются куски железных шлаков, фрагменты обожженной глины и вещи из культурного слоя.

Тип 3. Полуподземные горны с камерой кубической формы (рис. 4). Стенки вылеплены из глинистой почвы над плоским камнем на дне. Представление об этом типе металлургического объекта дает печь хорошей археологической сохранности, открытая на стоянке Итомиура (Мандрыка, Сенотрусова, 2013; Мандрыка, Сенотрусова, 2014). Она была устроена в яме округлой формы диаметром 50 см и глубиной не менее 35 см. На дно ямы был положен плоский камень размерами $30 \times 24 \times 5,5$ см. Полость плавильной камеры создавалась забутовкой пространства между стенками ямы, обложенными берестой и каким-то кубовидным предметом (возможно, бруском или квадратной опалубкой из досок). Стенки формовались из суглинистой почвы. Камера с выраженными на дне углами, сохранившаяся высота 20-22 см, размеры ровного дна $24 \times 24$ см. В двух противоположных стенках в 8 см выше дна устраивались фурмовые проходы диаметром до 6 см. В них 


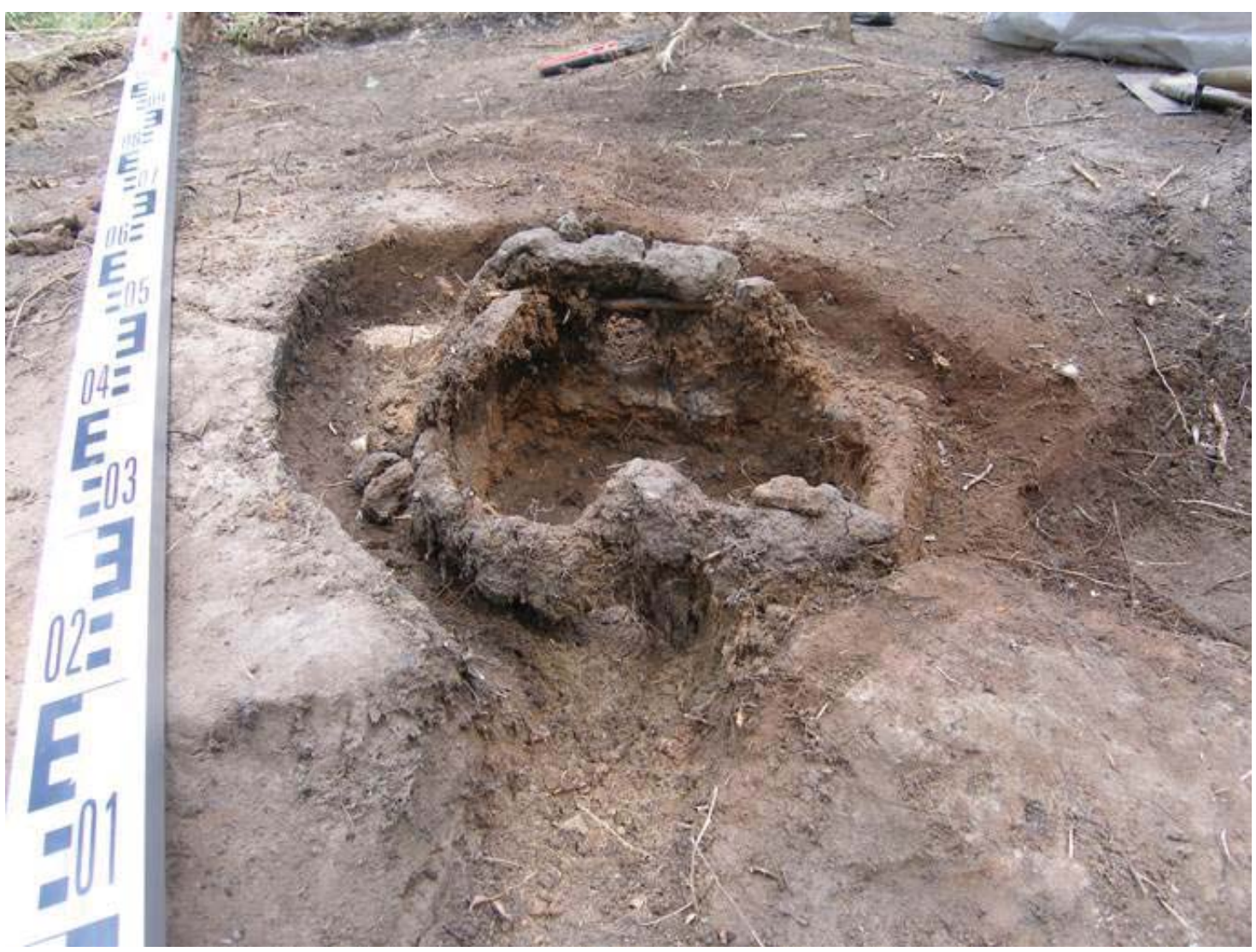

Рис. 4. Горн с камерой кубической формы из суглинка. Стоянка Итомиура.

Раскопки П.О. Сенотрусовой 2013 г.

Fig. 4. Furnace with a cubic loam chamber. Itomiura site. Excavations by P.O. Senotrusova of 2013.

вставлялись сопла. С восточной стороны печи отмечена яма размерами $0,7 \times 0,8$ м и глубиной до 24 см с неровным дном, заполненная красной прокаленной почвой с фрагментами древесного угля и мелкими кусками железного шлака. Верхняя часть печи лепилась из глины, она повторяла подземную часть горна, была кубовидной формы высотой не менее 20 см и с толщиной стенок $1-1,5$ см.

\section{Обсуждение результатов}

Горны первого типа известны на многих памятниках Нижнего Приангарья: на поселении Проспихинская Шивера-I, ОАН о. Каменном-I, стоянке Усть-Кова I, УстьЧадобец, Сергушкин-1, Пашина (Мандрыка и др., 2012, с. 41; Тимощенко, Быкова, Бочарова, 2013, с. 219; Харевич и др., 2011, с. 483; Гладилин, 1985, с. 169; Герман, Леонтьев, 2013, с. 62; Стоянка..., 2016, с. 56-61). Подобные углубленные металлургические горны были выделены А.В. Гладилиным в отдельный тип (тип 1б) и датированы им на основании двух радиоуглеродных дат (таблица № 1), а также аналогий с горнами из Минусинской котловины и о. Соснового IV-II вв. н. э. При этом он считал, что наземной части эти горны не имели.
Новые данные показывают, что датировка сыродутных горнов 1 типа достаточна широка, от IV в. до н. э. до XX века (табл. 1). Датировки скифским временем вызывают сомнения, так как были получены в 1980-е годы еще не в аккредитованных лабораториях. В печах тесинского времени, судя по рисункам, представленным А.В. Гладилиным, дно камеры было глиняным, в печах раннего и развитого Средневековья дном камеры выступал плоский камень, а в печи Нового времени со стоянки Пашина дно камеры оставалось земляным. Изменяются в истории металлургии Приангарья и объемы камеры: в средневековых сыродутных горнах диаметр камеры не превышал 25 см, а в Новое время встречаются камеры диаметром до 40 см. Отмеченное в горне на стоянке Пашина незначительное грушевидное расширение камеры в придонной части (Стоянка..., 2016, с. 60) связано, очевидно, с деформацией стенки из-за еe непрочности (от наличии в земле рядом какой-то пустоты, например, кротовины или хода сгнившего корня дерева, в которую затек расплавленный металл (чугун), что задокументировали авторы раскопок (Стоянка..., 2016 , рис. 65 , с. 58$)$ ). 
Таблища 1. Особенности устройства и радиоуглеродная датировка сыродутных горнов из памятников Нижней Ангары

Table 1. Structural features and radiocarbon dating of the catalan furnaces from the Lower Angara sites

\begin{tabular}{|c|c|c|c|c|c|}
\hline № & памятник & Описание печи & дата & лаборатория & ссылка \\
\hline 1 & Чадобец & $\begin{array}{c}\text { Тигль-сосуд, воздух } \\
\text { подавался через сопло }\end{array}$ & $2230 \pm 100$ & (КРИЛ-251) & Гладилин, 1985, с. 168 \\
\hline 2 & Усть-Кова & $\begin{array}{c}\text { Ямный горн, камера } \\
\text { обмазана глиной }\end{array}$ & $2450 \pm 50$ & (ГИН-252) & Гладилин, 1985, с. 168 \\
\hline 3 & Усть-Чадобец & $\begin{array}{c}\text { Ямный горн с фурмой, } \\
\text { камера в форме овала }\end{array}$ & $2000 \pm 100$ & (КРИЛ-231) & Гладилин, 1985, с. 170 \\
\hline 4 & В.С. Пашина & $\begin{array}{c}\text { Горн на каменном } \\
\text { фундаменте в яме, камера } \\
\text { цилиндрической формы, } \\
\text { с двумя фурмовыми } \\
\text { отверстиями }\end{array}$ & $1250 \pm 50$ & (ГИН-1743) & $\begin{array}{c}\text { Дроздов и др., 1978; } \\
\text { Гладилин, Ермолаев, Леонтьев, } \\
\text { 1986, с. 43; Гладилин, 1985, с. 171; } \\
\text { Леонтьев, 1999, с. 13, 20; Дроздов, } \\
\text { Леонтьев, Привалихин, 2005, с. 54; } \\
\text { Леонтьев, Дроздов, 2005 }\end{array}$ \\
\hline 5 & Итомиура & $\begin{array}{c}\text { Полуподземный горн, } \\
\text { камера кубовидной } \\
\text { формы, с двумя } \\
\text { фурмовыми отверстиями }\end{array}$ & $1660 \pm 70$ & $(\mathrm{COAH}-8950)$ & $\begin{array}{c}\text { Мандрыка, Сенотрусова, 2014, } \\
\text { с. } 74\end{array}$ \\
\hline 6 & $\begin{array}{c}\text { ПШ-IV } \\
\text { Горн № } 7\end{array}$ & $\begin{array}{c}\text { Полуподземный горн, } \\
\text { камера кубической } \\
\text { формы, часть стенок } \\
\text { сделана из камня }\end{array}$ & $975 \pm 35$ & (COAH-8639) & $\begin{array}{c}\text { Сенотрусова, Самородский, } \\
\text { Мандрыка. } 2016 \text {, с. } 142\end{array}$ \\
\hline 7 & $\begin{array}{c}\text { ПШ-IV } \\
\text { Горн № } 8\end{array}$ & $\begin{array}{c}\text { Полуподземный горн, } \\
\text { камера кубической } \\
\text { формы, стенки выложены } \\
\text { из камней } \\
\end{array}$ & $680 \pm 30$ & (COAH-8641) & $\begin{array}{c}\text { Сенотрусова, Самородский, } \\
\text { Мандрыка. } 2016 \text {, с. } 142\end{array}$ \\
\hline 8 & $\begin{array}{c}\text { ПШ-IV } \\
\text { Горн № } 9\end{array}$ & $\begin{array}{c}\text { Полуподземный горн, } \\
\text { камера цилиндрической } \\
\text { формы, стенки обмазаны } \\
\text { глиной } \\
\end{array}$ & $885 \pm 25$ & (COAH-8640) & $\begin{array}{c}\text { Сенотрусова, Самородский, } \\
\text { Мандрыка. } 2016 \text {, с. } 142\end{array}$ \\
\hline 9 & $\begin{array}{c}\text { Пашина } \\
\text { Объект 9Б }\end{array}$ & $\begin{array}{c}\text { Полуподземный горн, } \\
\text { с камерой из глины, } \\
\text { разрушен }\end{array}$ & $984 \pm 100$ & $(\mathrm{SPb}-216)$ & Стоянка ..., 2016, с. 56 \\
\hline 10 & $\begin{array}{c}\text { Пашина } \\
\text { Объект 9A }\end{array}$ & $\begin{array}{c}\text { Полуподземный горн, } \\
\text { с камерой из глины, } \\
\text { разрушен } \\
\end{array}$ & $2310 \pm 120$ & $(\mathrm{SPb}-219)$ & Стоянка ..., 2016, с. 56 \\
\hline 11 & $\begin{array}{c}\text { Пашина } \\
\text { Объект } 12\end{array}$ & $\begin{array}{c}\text { Полуподземный горн, } \\
\text { камера цилиндрическо- } \\
\text { грушевидной формы из } \\
\text { глины } \\
\end{array}$ & $135 \pm 20$ & $(\mathrm{SPb}-215)$ & Стоянка ..., 2016, с. 56 \\
\hline
\end{tabular}

Горны второго типа найдены на стоянках Пашина, Берямба, Усть-Карабула, Отико II, Проспихинская Шивера-IV (Гладилин, 1985, с. 171 ; Леонтьев, Дроздов, 2005, с. 390; Гревцов, Лысенко, Галухин, 2010, с. 510; Макаров, 2013, с. 134; Абдулов, Абдулов, Алтухов, 2013, с. 9; Сенотрусова, Самородский, Мандрыка, 2016). Горны этого типа были датированы А.В. Гладилиным второй половиной I тыс. н. э., он отмечал, что они могли использоваться вплоть до начала XX века (Гладилин, 1985, с. 171). Горны со стоянки Берямба отнесены авторами работ к Средним векам, точнее к VI-XII вв. (Гревцов, Лысенко,
Галухин, 2010, с. 509). Для двух горнов этого типа, № 7 и № 8 с Проспихинской ШиверыIV, по углю из заполнения плавильных камер получены радиоуглеродные даты (см. таблицу 1). Их калибровка показывает время сооружения горна № 7 в рамках XI - середины XII вв., а горна № 8 - с конца XIII до начала XIV вв.

Горны третьего типа, как на стоянке Итомиура, открыты еще в устье р. Муры и остаются пока не изученными. Датировка их в интервале III-VI вв. н. э. строится на данных радиоуглеродного датирования (табл. 1) и типологического сопоставления с первыми двумя типами. Представленный тип печей сохраня- 
ет строительный элемент печей первого типа (стенки из глины), но придает им новую кубовидную форму, которая станет характерной для горнов второго типа. Отсюда третий тип сыродутных горнов занимает как бы промежуточное положение между первым и вторым типами.

Среди всех известных и опубликованных металлургических объектов Нижнего Приангарья наземные теплотехнические сооружения для получения металлического железа из рудного неизвестны. Объекты, сложенные из камней на поверхности вокруг кострища, могли выступать кузнечными горнами. Сыродутные горны в обязательном порядке имели ямные основания. К индивидуальным особенностям горнов можно отнести форму камер, их устройство, присутствие плоских камней на дне плавильных камер, способы возведения наземных надстроек, использование органических материалов при их сооружении, расположение и количество фурмовых отверстий, наличие или отсутствие пригорновых ям и ряд других признаков. На их взаимном сочетании и выделяются отдельные таксоны.

В сопредельных Нижнему Приангарью районах Сибири теплотехнические металлургические объекты имеют несколько иной вид. В Томском Приобье получение железа из местных руд получает распространение только на рубеже I-II тыс. (Водясов, 2013, c. 128), при этом горны этого региона имели глиняный купол, сооруженный над небольшой ямой. Диаметр основания сооружения составлял 20-50 см, высота не более $0,7 \mathrm{~cm}$ (Водясов, 2012, с. 81). В Хакасско-Минусинской котловине в таштыкскую эпоху были широко распространены ямные горны разных размеров, чаще прямоугольной или овальной формы, с фурмой. Меха устанавливались на поверхности (Сунчугашев, 1979, с. 50). В Средневековье получают распространение горны с плавильной камерой прямоугольной формы, сложенные из плит песчаника, часто с пригорновой ямой (Сунчугашев, 1979, с. 99, 111). Датируются подобные сооружения VI-XII вв. В материалах Прибайкалья сыродутные горны также весьма далеки от нижнеангарских горнов (Харинский и др., 2013, c. 120; Харинский, Снопков, 2020). Истоки ангарской черной металлургии следует искать в памятниках хуннского круга культур, с распространением которых начинается широкое использование железа в южных районах Сибири (Мандрыка, 2012; Завьялов, Терехова, 2015).

\section{Выводы}

Таким образом, отмеченные сыродутные горны Нижней Ангары близки между собой и отражают развитие одной технологической традиции, появившейся в тесинское время с распространением памятников шилкинской культуры (Мандрыка, 2017). Доминирующим компонентом в ней выступали племена, подверженные влиянию хунну.

\section{ЛИТЕРАТУРА}

Абдулов Т.А., Абдулов А.Т., Алтухов В.В. Результаты спасательных археологических работ на многослойном геоархеологическом объекте Отико II // Евразия в Кайнозое. Стратиграфия, палеоэкология, культуры. 2013. №2. С. 7-18.

Адамов А.А., Данилов П.Г. Археологические исследования стоянки Сережкино в Северном Приангарье // Проблемы археологии, этнографии, антропологии Сибири и сопредельных территорий. T. XVI / Отв. ред. А.П. Деревянко, В.И. Молодин. Новосибирск: ИАЭТ СО РАН, 2010. С. 471-474.

Амзараков П.Б., Ковалева О.В. Предварительные результаты исследования памятников стоянка Рожково и остров Сосновый в Кежемском районе Красноярского края Проблемы археологии, этнографии, антропологии Сибири и сопредельных территорий. Т. XVI / Отв. ред. А.П. Деревянко, В.И. Молодин. Новосибирск: ИАЭТ СО РАН, 2010. С. 483-487.

Деревянко А.П., Цыбанков А.А., Постнов А.В., Славинский В.С., Выборнов А.В., Зольников И.Д., Деев Е.В., Присекайло А.А., Марковский Г.И., Дудко А.А. Богучанская археологическая экспедиция: очерк полевых исследований (2007-2012 годы) / Тр. Богучанской археологической экспедиции. Т. 1. Новосибирск: ИАЭТ СО РАН, 2015. 564 с.

Васильевский Р.С., Аксенов М.П. Археологические исследования в 1967 г. в зоне затопления УстьИлимской ГЭС // Материалы полевых исследований Дальневосточной археологической экспедиции. Вып. 2. / Отв. ред. А. П. Окладников. Новосибирск: Наука, 1971. С. 135-201.

Водясов Е.В. Средневековые сыродутные горны Шайтанского археологического микрорайона // Вестник ТГУ. 2012. № 359. С. 79-83

Водясов E.B. Начало освоения железорудных месторождений Обь-Томского междуречья // Вестник ТГУ. История. 2013. № 6 (26). С. 126-129. 
Гаркуша Ю.Н., Гришин А.Е., Марченко Ж.В., Казакова Е.А., Дудко А.А. Исследование разновременной стоянки и неолитического могильника Усть-Зелинда-1 (Северное Приангарье) // Проблемы археологии, этнографии, антропологии Сибири и сопредельных территорий. Т. XVIII. / Отв. ред. А.П. Деревянко, В.И. Молодин. Новосибирск: ИАЭТ СО РАН, 2012. С. 435-439.

Гладилин А.В. Металлургия Среднеангарья // Археологические исследования в районах новостроек Сибири / Отв. ред. В. И. Молодин Новосибирск: Наука, 1985. С. 167-180.

Гладилин А.В., Ермолаев А.В., Леонтьев В.П. Природно-климатические условия эпохи железного века в Северном Приангарье // Проблемы охраны и освоения культурно-исторических ландшафтов Сибири / Отв. ред. И. В. Асеев, Д. Я. Резун Новосибирск: Наука, 1986. С. 39-54.

Голубева E.B. Теория и практика экспериментально-трасологических исследований неметаллического инструментария раннего железного века - средневековья (на материалах южно-таежной зоны Средней Сибири). Красноярск: Сиб. федер. ун-т., 2016. 144 с.

Гревиов Ю.А., Лысенко Д.Н., Галухин Л.Л. Спасательные работы Берямбинского отряда Богучанской археологической экспедиции ИАЭТ СО РАН в 2010 году // Проблемы археологии, этнографии, антропологии Сибири и сопредельных территорий. T. XVI / Отв. ред. А.П. Деревянко, В.И. Молодин. Новосибирск: ИАЭТ СО РАН, 2010. С. 509-514.

Дроздов Н.И., Королева В.И., Пашинов А.М., Привалихин В.И. Исследования в Северном Приангарье // АО 1977 года / Отв. ред. Б.А. Рыбаков. М.: Наука, 1978. С. 226-227.

Дроздов Н.И., Леонтьев В.П., Привалихин В.И. К вопросу о хронологической принадлежности погребений стоянки Пашина в Северном Приангарье // Древности Приенисейской Сибири. Вып. IV / Отв. ред. Н.И. Дроздов. Красноярск: РИО ГОУ ВПО КГПУ им. В.П. Астафьева, 2005. С. 50-57.

Завьялов В.И., Терехова Н.Н. К проблеме становления железной индустрии на Среднем Енисее (технологический аспект) // КСИА. 2015. Вып. 238. С. 212-228.

Князева E.B. Технология металлургии и металлообработки на территории Нижнего Приангарья в средние века: опыт экспериментально-трасологических исследований // Вестник НГУ. Серия: История, филология. 2011. Т. 10. № 5. С. 108-116.

Князева Е.В., Мандрыка П.В., Сенотрусова П.О., Оводов Н.Д. Поселение раннего железного века и средневековья Проспихинская Шивера IV на Ангаре: палеоэкономический аспект // Древние культуры Монголии и Байкальской Сибири. Вып. 2. / Отв. ред. А.В. Харинский. Иркутск: Иркутский национальный исследовательский технический университет, 2011. С. 193-198.

Кондратов Н.M. Железоплавильные горны комплекса Проспихинская Шивера IV на Ангаре // Археология, этнография, палеоэкология Северной Евразии: проблемы, поиски, открытия / Отв. ред. Н.И. Дроздов. Красноярск: КГПУ им. В.П. Астафьева, 2011. С.163-164.

Леонтьев В.П. Железный век Северного Приангарья. Автореф. Дисс. ... канд. ист. наук. Новосибирск, 1999. 24 с.

Леонтьев В.П., Дроздов Н.И. К вопросу о развитии металлургии железа у племен Северного Приангарья по материалам стоянки Пашина // Проблемы археологии, этнографии, антропологии Сибири и сопредельных территорий. Т. ХІ. Ч. 1. / Отв. ред. А.П. Деревянко, В.И. Молодин. Новосибирск: ИАЭТ CO PAH, 2005. C. 390-393.

Макаров Н.П. Стоянка Усть-Карабула и вопросы археологии Северного Приангарья // Археологические исследования древностей Нижней Ангары и сопредельных территорий / Отв. ред. Л.Л. Карнаухова. Красноярск: КККМ, 2013. С. 130-175.

Мандрыка П.В. О появлении железа в южной тайге Среднего Енисея // Российский археологический ежегодник. № 2 / Глав. ред. Л.Б. Вишняцкий. СПб.: Изд-во С.-Петерб. ун-та, 2012. С. 400-411.

Мандрыка П.В. Культура гуннского времени в южной тайге долины Енисея // VIII Международная научная конференция «Древние культуры Монголии, Байкальской Сибири и Северного Китая». г. Чанчунь (Китай), 11-15 сентября 2017 г. Сборник тезисов и авторефератов / Отв. ред. Лин Юан. Чанчунь (Китай): Цзилиньский государственный университет, 2017. С. 217-227.

Мандрыка П.В., Князева Е.В. Каменные орудия средневекового поселения Проспихинская Шивера I: функционально-трасологический анализ // Вестник НГУ. Серия: История, филология. 2011. Т. 10. № 3. C. $155-162$.

Мандрыка П.В., Сенотрусова П.О. Производственная металлургическая площадка стоянки Итомиура в Северном Приангарье // Интеграция археологических и этнографических исследований: Сб. науч. тр.: в 2 т. Т. 1. / Отв. ред. Д. Дж. Андерсон и др. Иркутск: Изд-во ИрГТУ, 2013.С. 214-220. 
Мандрыка П.В., Сенотрусова П.О. Культурно-хронологические комплексы палеометалла и средневековья стоянки Итомиура в Северном Приангарье // Известия Иркутского государственного университета. Серия «Геоархеология. Этнология. Антропология». 2016. Т. 8. С. 63-81.

Мандрыка П.В., Титова Ю.А., Князева Е.В., Сенотрусова П.О. Поселение Проспихинская Шивера-І на Ангаре // Древности Приенисейской Сибири. Вып. V. / Отв. ред. П.В. Мандрыка. Красноярск: СФУ, 2012. C. 31-42.

Окладников А.П. Предварительный отчет о работе Ангарской археологической экспедиции в 1937 г. / Архив ИИМК. Ф. 2. Оп. 1937. Д. 222. Л. 16.

Окладников А.П. Отчет об исследованиях на Сосновом и Лесных островах на Ангаре летом 1952 г. / Архив ИИФиФ. 147 л.

Окладников А.П. Отчет о раскопках, осуществленных Ангарской археологической экспедицией на Лесном острове. 1953 г. / Архив ИИФиФ. 125 л.

Постнов А.B. Результаты полевых исследований стоянки Большая Пеленда // Проблемы археологии, этнографии, антропологии Сибири и сопредельных территорий. T. XVI / Отв. ред. А.П. Деревянко, В.И. Молодин. Новосибирск: ИАЭТ СО РАН, 2010. С. 565-568.

Рыбин Е.П., Кубан А.А., Мещерин М.Н., Фролов Я.В. Археологические работы на стоянках Игренькина Шивера и Колпаков ручей в зане затопления Богучанской ГЭС // Проблемы археологии, этнографии, антропологии Сибири и сопредельных территорий. Т. XVI / Отв. ред. А.П. Деревянко, В.И. Молодин. Новосибирск: ИАЭТ СО РАН, 2010. С. 575-582.

Сенотрусова П.О. Результаты разведочных работ в нижнем течении р. Муры // Древности Приенисейской Сибири. Вып. VI. / Отв. ред. П.В. Мандрыка. Красноярск: СФУ, 2013. С. 103-111.

Сенотрусова П.О., Самородский П.Н., Мандрыка П.В. Материалы по черной металлургии на комплексе Проспихинская Шивера IV в Нижнем Приангарье // Вестник НГУ. Серия: История, филология. 2016. Т. 15. № 5. С. 136-147.

Гришин А.Е., Марченко Ж.В., Гаркуша Ю.Н., Гурулёв Д.А., Шнайдер С.В., Кулик Н.А., Васильев С.К., Кербс E.A. Стоянка Пашина в Северном Приангарье (исследования 2008-2009 гг.) / Тр. Богучанской археологической экспедиции Т. 2. Новосибирск: ИАЭТ СО РАН, 2016. 168 с.

Сунчугашев Я.И. Древняя металлургия Хакасии. Эпоха железа. Новосибирск: Наука, 1979. 192 с.

Тимощенко А.А., Быкова М.В., Бочарова Е.Н. Новая металлургическая площадка в Северном Приангарье (по материалам ОАН о. Каменный (60 км) I) // Археология, этнология и антропология АТР. Междисциплинарный аспект. / Отв. ред. Н.Н. Крадин, Ф.Е. Ажимов. Владивосток: Изд. дом Дальневост. федерал. ун-та, 2013. С. 218-221.

Харевич В.М., Стасюк И.В., Акимова Е.В., Горельченкова О.А., Кукса Е.Н., Махлаева Ю.М., Томилова E.A. Исследование стоянки Усть-Кова I (пункт 2) в 2011 году // Проблемы археологии, этнографии, антропологии Сибири и сопредельных территорий.T. XVII. / Отв. ред. А.П. Деревянко, В.И. Молодин. Новосибирск: ИАЭТ СО РАН, 2011. С. 482-486.

Харинский А.В., Снопков С.В. Производство железа на территории Приольхонья (западное побережье озера Байкал) в XIII-VIV вв. // Известие Лаборатории древних технологий. 2020. Т. 16. № 3. С. $65-93$.

Харинский А.В., Снопков С.В., Казанский А.Ю., Матасова Г.Г., Кожевников Н.О., Амано Т. Металлургический центр Курма-28 (Приоольхонье) // Современные решения актуальных проблем евразийской археологии / Отв. ред. А.А. Тишкин. Барнаул: изд-во Алт. ун-та, 2013. С. 117-120.

Senotrusova P.O., Mandryka P.V. Blacsmithing of the lower Angara region population in the Middle ages (on materials from Prospikhinskaya Shivera-IV complex) // Ancient Metallurgy of the Sayan-Altai and East Asia. Vol. 1 / Ed. by Ya. Murakami and Yu. Esin. Abakan; Ehime: Ehime University Press, 2015. P. 137-144.

\section{Информация об авторах:}

Мандрыка Павел Владимирович, доктор исторических наук, заведующий сектором археологии, Сибирский федеральный университет (г. Красноярск, Россия); pmandryka@yandex.ru

Сенотрусова Полина Олеговна, кандидат исторических наук, старший научный сотрудник лаборатории археологии, этнографии и истории Сибири Гуманитарного института, Сибирский федеральный университет (г. Красноярск, Россия); Polllina1987@rambler.ru

\section{REFERENCES}

Abdulov, T. A., Abdulov, A. T., Altuhov, V. V. 2013. In Evraziia v Kainozoe. Stratigrafiia, paleoekologiia, kul'tury (Eurasia in the Cenozoic. Stratigraphy, Paleoecology, Cultures) 2, 7-18 (in Russian). 
Adamov, A. A., Danilov, P. G. 2010. In Derevianko, A. P., Molodin, V. I. (eds.). Problemy arkheologii, etnografii, antropologii Sibiri i sopredel'nykh territorii (Issues of Archaeology, Etnography and Anthropology of Siberia and the Adjoining Territories). Vol. 16. Novosibirsk: Institute of Archaeology and Ethnography of the Siberian Branch, Russian Academy of Sciences, 471-474. (in Russian).

Amzarakov, P. B., Kovaleva, O. V. 2010. In Derevianko, A. P., Molodin, V. I. (eds.). Problemy arkheologii, etnografi, antropologii Sibiri i sopredel'nykh territorii (Issues of Archaeology, Etnography and Anthropology of Siberia and the Adjoining Territories). Vol. 16. Novosibirsk: Institute of Archaeology and Ethnography of the Siberian Branch, Russian Academy of Sciences, 483-487 (in Russian).

Derevyanko, A. P., Tsybankov, A. A., Postnov, A. V., Slavinsky, V. S., Vybornov, A. V., Zol'nikov, I. D., Deev, E. V., Prisekailo, A. A., Markovsky G. I., Dudko, A. A. 2015. Boguchanskaia arkheologicheskaia ekspeditsiia: ocherk polevykh issledovanii (2007-2012 gody) (Boguchansk Archaeological Expedition: Essay on Field Studies (2007-2012)). Series: Trudy Boguchanskoi arkheologicheskoi ekspeditsii (Bulletin of the Boguchansk Archaeological Expedition). 1. Novosibirsk: Institute of Archaeology and Ethnography of the Siberian Branch, Russian Academy of Sciences (in Russian).

Vasil'evsky, R. S., Aksenov, M. P. 1971. In Okladnikov, A. P. (ed.). Materialy polevykh issledovanii Dal'nevostochnoi arkheologicheskoi ekspeditsii (Field Study Materials of the Far Eastern Archaeological Expedition) 2. Novosibirsk: "Nauka" Publ., 135-201 (in Russian).

Vodyasov, E. V. 2012. In Vestnik Tomskogo Gosudarstvennogo universiteta (Bulletin of the Tomsk State University) 359. 79-83 (in Russian).

Vodyasov, E. V. 2013. In Vestnik Tomskogo Gosudarstvennogo universiteta. Istoriia (Bulletin of the Tomsk State University: History) 26 (6). 126-129 (in Russian).

Garkusha, Yu. N., Grishin, A. E., Marchenko, Zh. V., Kazakova, E. A., Dudko, A. A. 2012. In Derevianko, A. P., Molodin, V. I. (eds.). Problemy arkheologii, etnografii, antropologii Sibiri i sopredel'nykh territorii (Issues of Archaeology, Etnography and Anthropology of Siberia and the Adjoining Territories). Vol. 18. Novosibirsk: Institute of Archaeology and Ethnography of the Siberian Branch, Russian Academy of Sciences, 435-439 (in Russian).

German, P. V., Leont'ev, S. N. 2013. In Arkheologicheskie issledovaniia drevnostei Nizhnei Angary $i$ sopredel'nykh territorii (Archaeological Studies of the Antiquities of the Lower Angara and Adjacent Territories). Krasnoiarsk: "KKKM" Publ., 57-72 (in Russian).

Gladilin, A. V. 1985. In Molodin, V. I. (ed.). Arkheologicheskie issledovaniia v raionakh novostroek Sibiri (Archaeological Studies in the New Urban Development Areas of Siberia). Novosibirsk: "Nauka" Publ., 167-180 (in Russian).

Gladilin, A. V., Ermolaev, A. V., Leont'ev, V. P. 1986. In Aseev, I. V., Rezun, D. Ya (eds.). Problemy okhrany $i$ osvoeniia kul'turno-istoricheskikh landshaftov Sibiri (Issues of Protection and Development of the Cultural and Historical Landscapes of Siberia). Novosibirsk: "Nauka" Publ., 39-54 (in Russian).

Golubeva, E. V. 2016. Teoriia i praktika eksperimental'no-trasologicheskikh issledovanii nemetallicheskogo instrumentariia rannego zheleznogo veka - srednevekov'ia (na materialakh iuzhno-taezhnoi zony Srednei Sibiri (Theory and Practice of Experimental Traceological Studies of Non-Metal Tools of the Early Iron Agethe Middle Ages (Based on Materials from the Southern Taiga Area of Central Siberia)). Krasnoiarsk: Siberian Federal University (in Russian).

Grevtsov, Yu. A., Lysenko, D. N., Galukhin, L. L. 2010. In Derevianko, A. P., Molodin, V. I. (eds.). Problemy arkheologii, etnografii, antropologii Sibiri i sopredel'nykh territorii (Issues of Archaeology, Etnography and Anthropology of Siberia and the Adjoining Territories). Vol. 16. Novosibirsk: Institute of Archaeology and Ethnography of the Siberian Branch, Russian Academy of Sciences, 509-514 (in Russian).

Drozdov, N. I., Koroleva, V. I., Pashinov, A. M., Privalihin, V. I. 1978. In Rybakov, B. A. (ed.). Arkheologicheskie otkrytiia 1977 g. (Archaeological Discoveries in 1977). Moscow: "Nauka" Publ., 226-227 (in Russian).

Drozdov, N. I., Leont'ev, V. P., Privalikhin, V. I. 2005. . In Drozdov, N. I. (ed.). Drevnosti Prieniseiskoi Sibiri (Antiquities of the Yenisei River Siberia) 4. Krasnoiarsk: Krasnoiarsk State Pedagogical University Publ., 50-57 (in Russian).

Zavyalov, V. I., Terekhova, N. N. 2015. In Kratkie soobshcheniia Instituta arkheologii (Brief Communications of the Institute of Archaeology) 238. 318-328 (in Russian).

Knyazeva, E. V. 2011. In Vestnik Novosibirskogo Gosudarstvennogo universiteta. Istoriia, filologiya (Bulletin of the Novosibirsk State University: History, Philology) 10 (5), 108-116 (in Russian).

Knyazeva, E. V., Mandryka, P. V., Senotrusova, P. O., Ovodov N. D. 2011. In Kharinskii, A. V. (ed.). Drevnie kul'tury Mongolii i Baikal'skoi Sibiri (Ancient Cultures of Mongolia and Baikal Siberia). Irkutsk: Irkutsk National Research Technical University, 193-198 (in Russian). 
Kondratov, N. M. 2011. In Drozdov, N. I. (ed.). Arkheologiia, etnografiia, paleoekologiia Severnoi Evrazii: problemy, poiski, otkrytiia (Archaeology, Ethnography, Paleoecology of Northern Eurasia: Issues, Searches, Discoveries). Krasnoiarsk: Krasnoiarsk State Pedagogical University Publ., 163-164 (in Russian).

Leont'ev, V. P. 1999. Zheleznyi vek Severnogo Priangar'ia (Iron Age of the Northern Angara Region). Thesis of Diss. of the Candidate of Historical Sciences. Novosibirsk (in Russian).

Leont'ev, V. P., Drozdov, N. I. 2005. In Derevianko, A. P., Molodin, V. I. (eds.). Problemy arkheologii, etnografi, antropologii Sibiri i sopredel'nykh territorii (Issues of Archaeology, Etnography and Anthropology of Siberia and the Adjoining Territories). Vol. 11. Part 1. Novosibirsk: Institute of Archaeology and Ethnography of the Siberian Branch, Russian Academy of Sciences, 390-393 (in Russian).

Makarov, N. P. 2013 In Arkheologicheskie issledovaniia drevnostei Nizhnei Angary i sopredel'nykh territorii (Archaeological Studies of the Antiquities of the Lower Angara and Adjacent Territories). Krasnoiarsk: "KKKM" Publ., 130-175 (in Russian).

Mandryka P. V. 2012. In Vishnyatsky, L. B. (ed.). Rossiiskii arkheologicheskii ezhegodnik (Russian Archaeological Yearbook) 2. Saint Petersburg: Saint Petersburg University, 400-411 (in Russian).

Mandryka, P. V. 2017. In Yuan', L. (ed.). VIII Mezhdunarodnaya nauchnaya konferentsiya «Drevnie kul'tury Mongolii, Baykal'skoy Sibiri i Severnogo Kitaya». g. Chanchun' (Kitay), 11-15 sentyabrya 2017 g. Sbornik tezisov i avtoreferatov ( $8^{\text {th }}$ International Scientific Conference "Ancient Cultures of Mongolia, Baikal Siberia and Northern China”, Changchun (China), September 11-15, 2017. Collection of Abstracts and Summaries). Chanchun' (Kitay): Jilin State University, 217-227 (in Russian).

Mandryka, P. V., Knyazeva, E. V. 2011. In Vestnik Novosibirskogo Gosudarstvennogo universiteta. Istoriia, filologiya (Bulletin of the Novosibirsk State University: History, Philology) 10 (3), 115-162 (in Russian).

Mandryka, P. V., Senotrusova, P. O. 2013. In Anderson, D. J., et al. (eds.). Integratsiia arkheologicheskikh i etnograficheskikh issledovanii (Integration of Archaeological and Ethnographic Studies) 1. Irkutsk: Irkutsk State Technical University, 214-220 (in Russian).

Mandryka P. V., Senotrusova P. O. 2014. In Izvestiia Irkutskogo gosudarstvennogo universiteta (Proceedings of Irkutsk State University). Series: «Geoarkheologiia. Etnologiia. Antropologiia (Geoarchaeology. Ethnology. Anthropology) 8. 63-81 (in Russian).

Mandryka, P. V., Titova, Yu. A., Knyazeva, E. V., Senotrusova, P. O. 2012. In Mandryka, P. V. (ed.). Drevnosti Prieniseiskoi Sibiri (Antiquities of the Yenisei River Siberia) 5. Krasnoiarsk: Siberian Federal University, 103-111 (in Russian).

Okladnikov, A. P. 1937. Predvaritel'nyi otchet o rabote Angarskoi arkheologicheskoi ekspeditsii v $1937 \mathrm{~g}$. (Preliminary report on the work of the Angara archaeological expedition in 1937) Archive of the Institute for the History of Material Culture, Russian Academy of Sciences. Fund 2. Inv. 1937, dossier 222 (in Russian).

Okladnikov, A. P. 1952. Otchet ob issledovaniiakh na Sosnovom i Lesnyh ostrovakh na Angare letom 1952 g. (Report on Studies on Sosnovy and Lesnoy Islands on the Angara in the Summer of 1952.) Archive of the Institute of History, Philology and Philosophy (in Russian).

Okladnikov, A. P. 1953. Otchet o raskopkakh, osushchestvlennykh Angarskoi arkheologicheskoi ekspeditsiei na Lesnom ostrove. $1953 \mathrm{~g}$. (Report on the Excavations by the Angarsk Archaeological Expedition on Lesnoy Island. 1953). Archive of the Institute of History, Philology and Philosophy(in Russian).

Postnov A. V. 2010. In Derevianko, A. P., Molodin, V. I. (eds.). Problemy arkheologii, etnografii, antropologii Sibiri i sopredel'nykh territorii (Issues of Archaeology, Etnography and Anthropology of Siberia and the Adjoining Territories). Vol. 16. Novosibirsk: Institute of Archaeology and Ethnography of the Siberian Branch, Russian Academy of Sciences, 565-568 (in Russian).

Rybin, E. P., Kuban, A. A., Meshcherin, M. N., Frolov, Ya. V. 2010. In Derevianko, A. P., Molodin, V. I. (eds.). Problemy arkheologii, etnografii, antropologii Sibiri i sopredel'nykh territorii (Issues of Archaeology, Etnography and Anthropology of Siberia and the Adjoining Territories). Vol. 16. Novosibirsk: Institute of Archaeology and Ethnography of the Siberian Branch, Russian Academy of Sciences, 575-582 (in Russian).

Senotrusova, P. O. 2013. In Mandryka, P. V. (ed.). Drevnosti Prieniseiskoi Sibiri (Antiquities of the Yenisei River Siberia) 6. Krasnoiarsk: Siberian Federal University, 103-111 (in Russian).

Senotrusova, P. O., Samorodskii, P. N., Mandryka, P. V. 2016. In Vestnik Novosibirskogo Gosudarstvennogo universiteta. Istoriia, filologiya (Bulletin of the Novosibirsk State University: History, Philology) 15 (5), 136-147 (in Russian).

Grishin, A. E., Marchenko, Zh. V., Garkusha, Yu. N., Gurulev, D. A., Shnaider, S. V., Kulik, N. A., Vasiliev, S. K., Kerbs, E. A. 2016. Stoianka Pashina v Severnom Priangar'e (issledovaniia 2008-2009 gg.) (Pashin's Site in the Northern Angara Region (Studies of 2008-2009.). Series: Trudy Boguchanskoi arkheologicheskoi 
ekspeditsii (Bulletin Boguchansk Archaeological Expedition). 2. Novosibirsk: Siberian Branch of the Russian Academy of Sciences, Institute for Archaeology and Ethnography, 193-197 (in Russian).

Sunchugashev, Ya. I. 1979. Drevniaia metallurgiia Khakasii. Epokha zheleza (Ancient Metallurgy of Khakassia. Iron Age). Novosibirsk: "Nauka" Publ. (in Russian).

Timoshchenko, A. A., Bykova, M. V., Bocharova, E. N. 2013. In Kradin, N. N., Azhimov, F. E. (ed.). Arkheologiia, etnologiia $i$ antropologiia ATR. Mezhdistsiplinarnyi aspekt (Archaeology, Ethnology and Anthropology of the Asia-Pacific Region. Interdisciplinary Aspect). Vladivostok: Far Eastern Federal University, 218-221 (in Russian).

Kharevich, V. M., Stasyuk, I. V., Akimova, E. V., Gorel'chenkova, O. A., Kuksa, E. N., Mahlaeva, Yu. M., Tomilova, E. A. In Derevianko, A. P., Molodin, V. I. (eds.). Problemy arkheologii, etnografii, antropologii Sibiri i sopredel'nykh territorii (Issues of Archaeology, Etnography and Anthropology of Siberia and the Adjoining Territories). Vol. 17. Novosibirsk: Institute of Archaeology and Ethnography of the Siberian Branch, Russian Academy of Sciences, 482-486 (in Russian).

Kharinskii, A. V., Snopkov, S. V., Kazanskii, A. Yu., Matasova, G. G., Kozhevnikov, N. O., Amano, T. 2013. In Tishkin, A. A. (ed.). Sovremennye resheniia aktual'nykh problem evraziiskoi arkheologii (Contemporary Solutions to the Current Issues of Eurasian Archaeology). Barnaul: Altai State University, 117-120 (in Russian).

Kharinskii, A. V., Snopkov, S. V. 2020. In Izvestiia laboratorii drevnikh tekhnologii (Bulletin of the Laboratory of Ancient Technologies) 16 (3). 65-93 (in Russian).

Senotrusova P.O., Mandryka P.V. 2015. In Murakami, Ya., Esin, Yu. (eds.). Ancient Metallurgy of the Sayan-Altai and East Asia. 1. Abakan; Ehime: Ehime University Press, 137-144 (in English).

\section{About the Authors:}

Mandryka Pavel V. Doctor of Historical Sciences, Head of the Archaeology Sector, Siberian Federal University, 79 Svobodny Ave., Krasnoyarsk, 660041, Russian Federation; pmandryka@yandex.ru

Senotrusova Polina O. Candidate of Historical Sciences, Siberian Federal University, 79 Svobodny Ave., Krasnoyarsk, 660041, Russian Federation; Polllina1987@rambler.ru

Статья поступила в журнал 01.04.2021 г. Статья принята к публикации 01.04.2021 г. Авторы внесли равноценный вклад в работу. 